\title{
Determination of Partition Coefficients of Selected Model Migrants between Polyethylene and Polypropylene and Nanocomposite Polypropylene
}

\author{
Pablo Otero-Pazos, ${ }^{1}$ David A. Pereira de Abreu, ${ }^{1}$ \\ Raquel Sendon, ${ }^{1}$ Ana Rodriguez Bernaldo de Quiros, ${ }^{1}$ Inmaculada Angulo, ${ }^{2}$ \\ Jose M. Cruz, ${ }^{3}$ and Perfecto Paseiro-Losada ${ }^{1}$ \\ ${ }^{1}$ Department of Analytical Chemistry, Nutrition and Bromatology, Faculty of Pharmacy, University of Santiago de Compostela, \\ 15782 Santiago de Compostela, Spain \\ ${ }^{2}$ Department of Plastic and Composites, GAIKER Research Centre, Zamudio, 48170 Bilbao, Spain \\ ${ }^{3}$ Department of Chemical Engineering, ETSEI, University of Vigo, Vigo, 36200 Pontevedra, Spain \\ Correspondence should be addressed to Raquel Sendon; raquel.sendon@usc.es
}

Received 8 November 2015; Accepted 24 December 2015

Academic Editor: Carola Esposito Corcione

Copyright (C) 2016 Pablo Otero-Pazos et al. This is an open access article distributed under the Creative Commons Attribution License, which permits unrestricted use, distribution, and reproduction in any medium, provided the original work is properly cited.

\begin{abstract}
Studies on nanoparticles have focused the attention of the researchers because they can produce nanocomposites that exhibit unexpected hybrid properties. Polymeric materials are commonly used in food packaging, but from the standpoint of food safety, one of the main concerns on the use of these materials is the potential migration of low molecular substances from the packaging into the food. The key parameters of this phenomenon are the diffusion and partition coefficients. Studies on migration from food packaging with nanomaterials are very scarce. This study is focused on the determination of partition coefficients of different model migrants between the low-density polyethylene (LDPE) and polypropylene (PP) and between LDPE and nanocomposite polypropylene (naPP). The results show that the incorporation of nanoparticles in polypropylene increases the mass transport of model migrants from LDPE to naPP. This quantity of migrants absorbed into PP and naPP depends partially on the nature of the polymer and slightly on the chemical features of the migrant. Relation $\left(R_{\mathrm{PP} / \text { naPP }}\right)$ between partition coefficient $K_{\mathrm{LDPE} / \mathrm{PP}}$ and partition coefficient $K_{\mathrm{LDPE} / \mathrm{naPP}}$ at $60^{\circ} \mathrm{C}$ and $80^{\circ} \mathrm{C}$ shows that only $\mathrm{BHT}$ at $60^{\circ} \mathrm{C}$ has a $R_{\mathrm{PP} / \mathrm{naPP}}$ less than 1 . On the other hand, bisphenol A has the highest $R_{\mathrm{PP} / \mathrm{naPP}}$ with approximately 50 times more.
\end{abstract}

\section{Introduction}

At the present time, multilayer systems are commonly used as food packaging. Plastic food packages contain additives (antioxidants, dyes, pigments, antifogging agents, stabilizers, and plasticizers) used to minimize degradation during processing, to facilitate processing and to increase stability during storage $[1,2]$. The contamination of foodstuffs with substances from the packaging material that can arise either from the packaging process itself (e.g., via overprinting labels) or from migration processes [3]. From the food safety point of view, it is important to remark that some substances (volatiles, additives, monomers, and oligomers) are able to migrate from packaging to foods. Migration includes two phenomena (partition and diffusion) that are important in determining the concentration of contaminants in a food system at any time. In the migration process, the kinetic (diffusion) and thermodynamic equilibrium (partition) can be defined as an exchange of mass and energy between the packaging and food $[4,5]$. Moreover, if food packaging is made up of various layers then it is important to know the capacity of substances to pass through them.

Measurement of the rate at which the diffusion process occurs is expressed in terms of diffusion coefficient $\left(\mathrm{cm}^{2} \mathrm{~s}^{-1}\right)$. The classical theory used to model the diffusion process is 
based on Fick's laws. Diffusion $(D)$ is based on the fact that the rate of transfer $(R)$ of a migrant passing perpendicularly through unit area of a section is proportional to the concentration gradient between the two sides of the packaging: $R=\partial C / \partial t=-D(C)(\mathrm{d} C / \mathrm{d} X)$. In general, $D$ is a function of the local diffusant concentration, $C\left(\mathrm{~mol} \mathrm{~m}^{-3}\right), t$ is the time (s), and $X$ is the thickness of the material (m) $[5,6]$. Amongst plastics, the highest diffusion rates occur in polyolefins, especially low-density polyethylene (LDPE) films. LDPE film was therefore chosen for the migration tests because it is widely used and provides a picture of the "worst case scenarios" [7]. Polypropylene (PP) is one of the most polyolefins used in food because it provides mechanical properties at low cost. Other vantages are their resistance to water vapor, acids, bases, grease, and solvents. The amount of package components that may migrate between layers of multilayer packaging material depends on the chemical and physical properties of them and the material itself. Different factors like partition coefficient, migrant concentration, time, temperature, packaging composition, molecular weight, solubility, diffusivity, and structures are the main controlling factors in migration $[5,8,9]$. In a multilayer packaging system, migrant transfer occurs to reach thermodynamic equilibrium. A partition coefficient $(K)$ is defined as the ratio of migrant concentration in the packaging material $C_{p 1}$ and its concentration in another packaging material phase, $C_{p 2}$ at equilibrium. $K$ is defined as $K=$ $C_{p 1} / C_{p 2}$. When $K=1$, the migrant concentration in each packaging material is equal, at equilibrium. $K$ is higher when more migrant quantity is absorbed into packaging material 1 than in packaging material 2. Molecular size and structure of migrant and structure of polymeric matrix are the main factors that affect the partition coefficient [5].

The approach of the European Commission (EC) in controlling the safety of food packaging and other food-contact materials has been to assign specific migration limits (SML) to those substances with potential adverse toxicological properties. The SML restricts the quantity of the substance allowed to migrate into foods or food simulants. For instance, the SML established for some of the model substances evaluated in this study are $0.6 \mathrm{mg} / \mathrm{kg}$ for bisphenol A and Uvitex and $3 \mathrm{mg} / \mathrm{kg}$ for butylated hydroxyl toluene. Migration limits are based on the acceptable daily intake/tolerable daily intake established by the European Food Safety Authority for the substance in question and on the assumption that a person weighing $60 \mathrm{~kg}$ eats $1 \mathrm{~kg}$ of food each day, which has been packaged in the same material. One important consideration in the migration test condition is the ratio of the volume of the simulant to the area of the sample. The conventional value considered by the $\mathrm{EC}, 6 \mathrm{dm}^{2} / \mathrm{kg}$, is used in most cases. In some instances, where the additive is readily soluble in the simulant, it is considered acceptable to increase this ratio to improve the sensitivity of the analysis. Experimental studies of all these migrations are time consuming and highly expensive [10-13]. Through the mathematical model, experimental migration tests only will be carried out when the predicted migration values are higher than those established by legislation. For those reasons, it is interesting to get a mathematical model that allows predicting theses distribution processes.
Moreover, nanotechnology is driving a long list of developments offering many alternatives. Organic-inorganic nanocomposites are compounds that exhibit hybrid properties derived from synergistic reactions between the two components. Nanocomposites based on organic polymers and inorganic clay minerals consisting of silicate layers are one of the most promising composite systems. Inside this system, a nanocompound can be intercalated or exfoliated, depending on the degree of dispersal of the nanoparticle between polymeric chains; however, a mixture of the two morphologies is often found. If the nanoparticles are completely dispersed between the polymeric chains, the nanocompound is exfoliated [14-17]; if they are not it is intercalated. Packages with exfoliated nanoparticles show better barrier properties than packages with intercalated nanoparticles. In general, the nanocomposites have been found to provide effective barriers to gaseous diffusion $[16,17]$. Nevertheless, for its use in the field of food-contact materials in the European Union they should be specifically authorized, and at this moment only titanium nitride nanoparticles are approved for use as additives in polyethylene terephthalate (PET) intended to come into contact with foodstuffs (Commission Regulation (EU) number 10/2011 of 14 January 2011) [18].

The present study is focused on the determination of partition coefficients of trans,trans-1,4-diphenyl-1,3-butadiene (DPBD), 5-chloro-2-(2,4-dichlorophenoxy)phenol (triclosan), Benzophenone, 2,5-bis(5-tert-butyl-2-benzoxazolyl) thiophene (Uvitex $\mathrm{OB}^{\circ}$ ), diphenyl phthalate (DPP), isopropyl9H-thioxanthen-9-one (ITX), butylated hydroxyl toluene (BHT), and bisphenol A (BPA) between the LDPE and polypropylene (PP) and between LDPE and nanocomposite polypropylene (naPP). Benzophenone and ITX are photoinitiators in inks, employed to print food packaging surfaces; DPBD is a fluorescent whitening agent; triclosan is a broadspectrum antimicrobial compound; DPP is a plasticizer that improves the performance of polyvinylpyrrolidone; BPA is used in the production of polycarbonate and epoxy resins, flame retardants, and other products; BHT is a small phenolic antioxidant, used in plastics at levels between hundreds of and a few thousand mg per kg as plastic stabilizer, and Uvitex OB is an optical brightening agent $[3,7,13,19-22]$. Selection of these substances was made on the basis of their representativeness as potential migrants from food-contact materials so that the results can be extrapolated to other substances of similar characteristics. The results were discussed in terms of the parameters that may have the greatest effect on migration.

\section{Materials and Methods}

2.1. Materials. The nanoclay used is natural montmorillonites, modified with a quaternary ammonium salt to facilitate dispersal in the polymeric matrix. Cloisite 15 A nanoparticles were used (provided by Southern Clay Product, Texas, USA; http://www.byk.com). Cloisite $15 \mathrm{~A}$ has an average particle size of $6 \mu \mathrm{m}$ and cationic exchange capacity of $125 \mathrm{meq} / 100 \mathrm{~g}$ of clay. Montmorillonite is suitable for incorporation in an apolar polymeric matrix such as polypropylene. The polypropylene selected was a copolymer of 
intermediate-high fluidity (ISPLEN PB $171 \mathrm{H1M}$ ), with MFI: $9.5 \mathrm{~g} / 10 \mathrm{~min}$, ISO $1133\left(230^{\circ} \mathrm{C} ; 2.16 \mathrm{~kg}\right)$.

2.2. Reagents and Standard Solutions. All reagents were of analytical grade. Ethanol, acetonitrile, and tetrahydrofuran were purchased from Merck (Darmstadt, Germany). Water used for all solutions was obtained from a Milli-Q water purification system (Millipore; Bedford, MA).

Model migrants standards were obtained as follows: Benzophenone and DPBD (98\%) were from Sigma-Aldrich (Steinheim, Germany); triclosan (97\%), Uvitex OB ( $\geq 99.0 \%)$, and BHT $(\geq 99.0 \%)$ were from Fluka (Steinheim, Germany); DPP $(\geq 99.0 \%)$, BPA $(\geq 99.0 \%)$ and ITX $(97 \%)$ were from Aldrich-Chemie (Steinheim, Germany). Stock standard solutions were prepared in ethanol and stored in amber flasks at $4^{\circ} \mathrm{C}$.

2.3. Film Samples. Films of LDPE were spiked with the migrants by extrusion process:

(i) LDPE film (thickness: $397.7 \pm 13.9 \mu \mathrm{m}$; $C_{\text {Benzophenone }}=$ $417.7 \pm 67.4 \mu \mathrm{g} \cdot \mathrm{g}^{-1} ; C_{\mathrm{DPBD}}=755.0 \pm 31.6 \mu \mathrm{g} \cdot \mathrm{g}^{-1} ;$ $C_{\text {Uvitex }}=900.3 \pm 55.2 \mu \mathrm{g} \cdot \mathrm{g}^{-1}$ ) was spiked with Benzophenone, DPBD, and Uvitex OB.

(ii) LDPE film (thickness: $410.6 \pm 16.7 \mu \mathrm{m} ; C_{\mathrm{DPP}}=457.3 \pm$ $113.2 \mu \mathrm{g} \cdot \mathrm{g}^{-1} ; C_{\mathrm{ITX}}=1138.0 \pm 206.9 \mu \mathrm{g} \cdot \mathrm{g}^{-1} ; C_{\mathrm{BHT}}=$ $839.8 \pm 170.3 \mu \mathrm{g} \cdot \mathrm{g}^{-1}$ ) was spiked with DPP, ITX, and BHT.

(iii) LDPE film (thickness: $394.8 \pm 17.6 \mu \mathrm{m} ; C_{\mathrm{BPA}}=933.7 \pm$ $\left.57.5 \mu \mathrm{g} \cdot \mathrm{g}^{-1} ; C_{\text {Triclosan }}=1233.1 \pm 85.1 \mu \mathrm{g} \cdot \mathrm{g}^{-1}\right)$ was spiked with BPA and triclosan.

The obtaining of the exfoliated film was previously described by Pereira de Abreu et al. [16].

A polypropylene masterbatch was used to elaborate that the nanocomposite polypropylene (naPP) film contained equal percentages of polypropylene and polypropylene modified with maleic anhydride and Cloisite $15 \mathrm{~A}(\mathrm{C} 15 \mathrm{~A})$. This masterbatch was prepared in the rollers at temperature of $160^{\circ} \mathrm{C}$. The resulting mixture was then crushed and diluted in the PP matrix by compounding in a double screw extruder (MIKE 27 GL-36 D LEISTRITZ) (screw diameter: $27 \mathrm{~mm}$, screw length: $36 \times D$, and screw speed range: $10-400 \mathrm{rpm}$ ).

For both the PP and its nanocompound, the following conditions were used in the extruder: barrel was set to $160-$ $170^{\circ} \mathrm{C}$; Zones I and II were at $160^{\circ} \mathrm{C}$, Zones III, IV, and V were at $163^{\circ} \mathrm{C}$, Zones VI, VII, and VIII were at $165^{\circ} \mathrm{C}$, and Zone IX was at $170^{\circ} \mathrm{C}$. The inorganic content of the samples was determined by measuring the weight before and after burning the organic component. Screw speed was set to $300 \mathrm{rpm}$ with a maximum temperature of $170^{\circ} \mathrm{C}$ for the PP. The obtained pellet was passed through the double screw extruder twice to homogenize the mixture thoroughly.

2.4. Analytical Procedure. To carry out partition coefficients calculation, LDPE, PP, and naPP were cut in pieces of $4 \times$ $4 \mathrm{~cm}^{2}$. The thickness along the film was measured to obtain an average value. LDPE film was put into contact with one face
TABLE 1: High performance liquid chromatography parameters employed in the analysis of Benzophenone, diphenylbutadiene (DPBD), and Uvitex.

\begin{tabular}{lccc}
\hline Injection volume & \multicolumn{3}{c}{$20 \mu \mathrm{L}$} \\
\hline Eluents & A: Milli-Q water \\
& B: THF 30\% methanolic solution (v/v) \\
\hline & Time (min) & \% Eluent A & \% Eluent B \\
\hline \multirow{4}{*}{ Eluent gradient } & 4 & 30 & 70 \\
& 10 & 30 & 70 \\
& 17 & 0 & 100 \\
& \multicolumn{3}{c}{ Posttime: 3 minutes } \\
\hline \multirow{4}{*}{ Detection } & Substance & UV (nm) \\
& Benzophenone & \multicolumn{2}{c}{256} \\
& DPBD & 330 \\
\hline
\end{tabular}

of PP or naPP. Samples were then wrapped with aluminum foil to protect them from the light and were placed inside a plastic bag and incubated in the oven at 60 and $80^{\circ} \mathrm{C}$. The incubation times used at $60^{\circ} \mathrm{C}$ were 40,55 , and 70 days and at $80^{\circ} \mathrm{C}$ were 25,40 , and 60 days, respectively. Then, at selected times, the set was withdrawn of the oven and the spiked LDPE film and the other plastic (PP or naPP) were separated. After this, an extraction of the selected migrants from spiked LDPE, $\mathrm{PP}$, and naPP films was made. The films were extracted in a $60 \mathrm{~mL}$ amber flask with $50 \mathrm{~mL}$ of ethanol for 6 hours at $70^{\circ} \mathrm{C}$. After this time, the flask was removed from the oven and the film was separated from the liquid phase. Then an aliquot of this liquid phase was filtered by a $0.50 \mu \mathrm{m}$ filter and analyzed by HPLC.

\subsection{High-Performance Liquid Chromatography Analysis.} The HPLC-DAD-FLD system (Hewlett-Packard, Waldbronn, Germany) was fitted with a HP1100 quaternary pump, a degassing device, an autosampler, a column thermostatting system, a diode array UV detector, and a fluorescence array detector. HP ChemStation chromatographic software was used for data acquisition. Chromatographic separation was performed on a Kromasil ODS C18 column $(25 \times 0.32 \mathrm{~cm} \mathrm{ID,}$ $5 \mu \mathrm{m}$ particle size) at $30^{\circ} \mathrm{C}$ and a flow rate of $0.5 \mathrm{~mL} \cdot \mathrm{min}^{-1}$; detailed analytical conditions are shown in Tables 1, 2, and 3.

\section{Results and Discussion}

Model migrants were selected based on their structure and chemical properties, trying to cover the maximum area in terms of molecular size and polarity.

Ranges of temperature and time exposition were selected seeking a compromise between the speed of the assay and the stability of the molecules. Thus, $60^{\circ} \mathrm{C}$ and $80^{\circ} \mathrm{C}$ were chosen, with exposure times of 40,55, and 70 days and 25,40 , and 60 days, respectively.

Effectiveness of extraction procedure was tested in films spiked with the selected substances. These films were 
TABLE 2: High performance liquid chromatography parameters employed in the analysis of diphenyl phthalate (DPP), 2-isopropylthioxanthone (ITX), and butylated hydroxyl toluene (BHT).

\begin{tabular}{lccc}
\hline Injection volume & \multicolumn{3}{c}{$10 \mu \mathrm{L}$} \\
\hline Eluents & \multicolumn{3}{c}{$\begin{array}{c}\text { A: Milli-Q water } \\
\text { B: Acetonitrile }\end{array}$} \\
\hline & Time (min) & \% Eluent A & \% Eluent B \\
\hline \multirow{3}{*}{ Eluent gradient } & 0 & 40 & 60 \\
& 1 & 40 & 60 \\
& 17 & 0 & 100 \\
& 20 & 0 & 100 \\
\hline \multirow{3}{*}{ Detection } & Substance & DAD (nm) & FLD (nm) \\
& DPP & 205 & - \\
& ITX & - & Ex 250; Em 410 \\
& BHT & 205 & - \\
\hline
\end{tabular}

TABLE 3: High performance liquid chromatography parameters employed in the analysis of bisphenol A (BPA) and triclosan.

\begin{tabular}{lccc}
\hline Injection volume & \multicolumn{3}{c}{$10 \mu \mathrm{L}$} \\
\hline Eluents & \multicolumn{3}{c}{ A: Milli-Q water } \\
& B: Acetonitrile \\
\hline & Time (min) & \% Eluent A & $\%$ Eluent B \\
\hline \multirow{3}{*}{ Eluent gradient } & 3 & 40 & 60 \\
& 9 & 40 & 60 \\
& 17 & 0 & 100 \\
& \multicolumn{4}{c}{ Posttime: 5 minutes } \\
\hline \multirow{2}{*}{ Detection } & Substance & DAD (nm) & FLD (nm) \\
& Triclosan & 205 & - \\
\hline
\end{tabular}

TABLE 4: Calibration curves and retention times of analyzed substances.

\begin{tabular}{lccc}
\hline Substance & $R t(\min )$ & $R^{2}$ & Equation \\
\hline Benzophenone & 5.3 & 0.99998 & $y=216.28 x-5.6776$ \\
DPBD & 12.7 & 0.99988 & $y=567.67 x-22.856$ \\
Uvitex & 14.8 & 0.99998 & $y=260.44 x+5.4778$ \\
DPP & 11.7 & 0.99999 & $y=174.88 x+0.5316$ \\
ITX & 16.8 & 0.99997 & $y=262.77 x+1.5187$ \\
BHT & 17.8 & 0.99950 & $y=161.96 x+74.026$ \\
Bisphenol A & 4.1 & 0.99999 & $y=662.48 x-1.731$ \\
Triclosan & 11.0 & 0.99999 & $y=239.82 x+2.327$ \\
\hline
\end{tabular}

extracted several times. Subsequent extractions of the film resulted in quantities of substances that were undetectable.

Quantification was obtained using a series of standards of selected substances solutions of known concentration. Calibration curves were constructed using five concentration levels and they were fitted to linear equations within the $0.25-$ $5 \mu \mathrm{g} \mathrm{mL}^{-1}$ range. The equations are shown in Table 4.
Partition coefficient LDPE/PP or naPP for each model substance was calculated using the following equation:

$$
\begin{array}{r}
K_{\mathrm{LDPE} / \mathrm{PP}}=\frac{C_{\mathrm{LDPEeq}}}{C_{\text {PPeq }}}, \\
K_{\mathrm{LDPE} / \mathrm{naPP}}=\frac{C_{\text {LDPEeq }}}{C_{\text {naPPeq }}},
\end{array}
$$

where $K_{\mathrm{LDPE} / \mathrm{PP}}$ is the partition coefficient between LDPE and PP; $K_{\mathrm{LDPE} / \mathrm{naPP}}$ is the partition coefficient between LDPE and naPP; $C_{\mathrm{PPeq}}$ is the concentration of substance in PP at equilibrium, in $\mu \mathrm{g} \mathrm{g}^{-1} ; C_{\text {naPPeq }}$ is the concentration of substance in naPP at equilibrium, in $\mu \mathrm{gg}^{-1} ; C_{\text {LDPEeq }}$ is the concentration of substance in the LDPE at equilibrium, in $\mu \mathrm{g} \mathrm{g}^{-1}$.

The partition coefficient of low-density polyethylene/polypropylene $\left(K_{\mathrm{LDPE} / \mathrm{PP}}\right)$ and low-density polyethylene/nanocomposite polypropylene $\left(K_{\mathrm{LDPE} / \mathrm{naPP}}\right)$, that is, the relative solubility of the migrants at equilibrium between the polyethylene and the polypropylene or nanocomposite polypropylene, is shown in Tables 5 and 6, respectively.

The partition coefficient values correspond to the relative solubility of the migrant at equilibrium between the polyethylene and the polypropylene or nanocomposite polypropylene [23]. Benzophenone, DPP, DPBD, BHT, ITX, and triclosan show a $K_{\mathrm{LDPE} / \mathrm{PP}}$ near to 1 . Because of the composition of polyethylene -[- $\mathrm{CH} 2-\mathrm{CH} 2-] \mathrm{n}$ - and polypropylene -[- $\mathrm{CH} 2-$ $\mathrm{CH}(\mathrm{CH} 2)-] n-$, with a similar structural base, these results were expected, whereas in the cases of Uvitex and bisphenol A the equilibrium was not reached at the end of the assay (i.e., at $60^{\circ} \mathrm{C}, 70$ days or at $80^{\circ} \mathrm{C}, 60$ days). The molecular size, chemical structure, and physicochemical properties (polarity, solubility, and hydrogen bonding) of migrants and type of packaging are important parameters affecting partition coefficient. Due to the large sizes of the polymer molecules, the secondary bond forces (van der Waals forces and hydrogen bonding) assume much greater roles in influencing physical properties than they do in small organic molecules [24]. Smaller molecules are absorbed more rapidly because they have a greater diffusivity than larger molecules. In fact, the partition coefficient of a series of compounds with the same functional group (i.e., esters or aldehydes) increased with increasing carbon chain length [5, 25-30]. The alcohols in aqueous solutions increase its partition coefficients to increase its molecular weight.

The differences in polarity of migrant and polymer are another important factor in the absorption process [5]. Alcohols and short-chained esters (polar substances) have higher partition coefficients in the oil/polymer system than in the water/polymer system, while aldehydes (long carbon nonpolar chains) have lower partition coefficients in the oil/polymer than in the water/polymer [29]. In mixtures, some compounds exhibit a lower absorption rate than systems containing the individual compounds. This effect could be due to the fact that the absorbed components change the properties of polymer and/or the compounds compete for a limited number of active sorption sites $[29,30]$. When more than one type of solids is present, alcohols preferentially are adsorbed to 
TABLe 5: Partition coefficient of polyethylene/polypropylene $\left(K_{\mathrm{LDPE} / \mathrm{PP}}\right)$ at $60^{\circ} \mathrm{C}$ and $80^{\circ} \mathrm{C}$ for all substances studied.

\begin{tabular}{|c|c|c|c|c|c|c|c|}
\hline Model migrant & Temperature & Time & $K_{\mathrm{LDPE} / \mathrm{PP}}$ & Model migrant & Temperature & Time & $K_{\mathrm{LDPE} / \mathrm{PP}}$ \\
\hline \multirow{6}{*}{ Benzophenone } & & 40 days & 0.86 & \multirow{6}{*}{ DPP } & \multirow{3}{*}{$60^{\circ} \mathrm{C}$} & 40 days & 0.86 \\
\hline & $60^{\circ} \mathrm{C}$ & 55 days & 0.84 & & & 55 days & 1.02 \\
\hline & & 70 days & 0.86 & & & 70 days & 0.89 \\
\hline & \multirow{3}{*}{$80^{\circ} \mathrm{C}$} & 25 days & 1.08 & & \multirow{3}{*}{$80^{\circ} \mathrm{C}$} & 25 days & 1.21 \\
\hline & & 40 days & 1.04 & & & 40 days & 1.04 \\
\hline & & 60 days & 1.03 & & & 60 days & 1.16 \\
\hline \multirow{6}{*}{ DPBD } & \multirow{3}{*}{$60^{\circ} \mathrm{C}$} & 40 days & 1.16 & & \multirow{3}{*}{$60^{\circ} \mathrm{C}$} & 40 days & 0.62 \\
\hline & & 55 days & 1.15 & & & 55 days & 0.66 \\
\hline & & 70 days & 1.09 & BHT & & 70 days & 0.56 \\
\hline & \multirow{3}{*}{$80^{\circ} \mathrm{C}$} & 25 days & 1.36 & ВН1 & \multirow{3}{*}{$80^{\circ} \mathrm{C}$} & 25 days & 0.90 \\
\hline & & 40 days & 1.31 & & & 40 days & 0.67 \\
\hline & & 60 days & 1.36 & & & 60 days & 0.86 \\
\hline \multirow{6}{*}{ Uvitex OB } & \multirow{3}{*}{$60^{\circ} \mathrm{C}$} & 40 days & 41.35 & \multirow{6}{*}{ Bisphenol A } & \multirow{3}{*}{$60^{\circ} \mathrm{C}$} & 40 days & 14.23 \\
\hline & & 55 days & 16.43 & & & 55 days & 14.13 \\
\hline & & 70 days & 9.42 & & & 70 days & 12.05 \\
\hline & \multirow{3}{*}{$80^{\circ} \mathrm{C}$} & 25 days & 6.26 & & \multirow{3}{*}{$80^{\circ} \mathrm{C}$} & 25 days & 8.19 \\
\hline & & 40 days & 4.50 & & & 40 days & 7.17 \\
\hline & & 60 days & 3.61 & & & 60 days & 5.70 \\
\hline \multirow{6}{*}{ ITX } & \multirow{3}{*}{$60^{\circ} \mathrm{C}$} & 40 days & 0.99 & & \multirow{3}{*}{$60^{\circ} \mathrm{C}$} & 40 days & 0.88 \\
\hline & & 55 days & 1.05 & & & 55 days & 0.93 \\
\hline & & 70 days & 0.99 & Triclosan & & 70 days & 0.91 \\
\hline & \multirow{3}{*}{$80^{\circ} \mathrm{C}$} & 25 days & 1.26 & 11. & \multirow{3}{*}{$80^{\circ} \mathrm{C}$} & 25 days & 1.13 \\
\hline & & 40 days & 1.07 & & & 40 days & 1.12 \\
\hline & & 60 days & 1.23 & & & 60 days & 1.15 \\
\hline
\end{tabular}

the solid with higher affinity for alcohols, until all binding sites on the solid have been occupied. Silica and soy protein increase solubility of alcohols in water by adsorbing them through hydrophobic association and/or hydrogen bonds [31].

Some of these factors could be the reasons because the diffusion for Uvitex and bisphenol A was lower than the rest of compounds and the equilibrium was not achieved. However, the $K_{\mathrm{LDPE} / \mathrm{PP}}$ should be close to 1 when the equilibrium will be reached.

PP has no polar groups in its backbone and the homogeneous dispersion of the silicate layers in PP is problematic without the utilization of a functional oligomer (maleic anhydride (MA) modified PP oligomer). There are two important factors in terms of the structures of the oligomers in order to obtain the complete homogeneous dispersion of the silicate layers. The oligomers should include a certain amount of polar groups to be intercalated between silicate layers through hydrogen bonding and the oligomers should be well miscible with PP. Functional oligomer is intercalated into the silicate layers at the first stage of the mixing process because the driving force of the intercalation originated from the strong hydrogen bonding between the maleic anhydride group (or $\mathrm{COOH}$ group generated from the hydrolysis of the maleic anhydride group) and the oxygen groups of the silicates. The interlayer spacing of the clay is increased and the interactions of the layers are decreased. Then, intercalated clays with the oligomers can enter in contact with PP under a strong shear field. If the miscibility of PP-MA with PP is good enough to disperse at the molecular level, the exfoliation of the intercalated clay should take place smoothly [32, 33]. Polymer/silicate nanocomposites have better properties that include high barrier properties, improved tensile characteristics, higher heat deflection temperature, better scratch resistance, and increased flame retardancy $[13,16,17,34]$. Observing results obtained, only in the cases of the Uvitex and bisphenol $\mathrm{A}$ at $60^{\circ} \mathrm{C}$ (70 days) it was not possible to reach equilibrium in the LDPE/naPP system. Triclosan, bisphenol $\left(80^{\circ} \mathrm{C}\right)$, and DPP show the smallest partition coefficient of low-density polyethylene/nanocomposite polypropylene $\left(K_{\mathrm{LDPE} / \mathrm{naPP}}\right)$, while Uvitex $\left(80^{\circ} \mathrm{C}\right)$ has the biggest $K_{\mathrm{LDPE} / \mathrm{naPP}}$. Table 7 shows the properties of the substances used in this study. The molecular size, chemical structure, and physicochemical properties of migrants and naPP characteristics could explain these results. These substances have the capacity to form secondary bond forces, only DPBD has no polar surface area. The polar surface area of a molecule is defined as the area of its van der Waals surface that arises from oxygen or nitrogen atoms or hydrogen atoms attached to oxygen or nitrogen atoms. As such, it is clearly related to the capacity of a compound to form hydrogen bonds [35]. But DPBD can form secondary bond forces (van der Waals forces). naPP has polar zones where the exfoliated nanoparticles and maleic anhydride group are staying. Maleic anhydride group can also 
TABLE 6: Partition coefficient of polyethylene/nanocomposite polypropylene $\left(K_{\mathrm{LDPE} / \mathrm{naPP}}\right)$ at $60^{\circ} \mathrm{C}$ and $80^{\circ} \mathrm{C}$ for all substances studied.

\begin{tabular}{|c|c|c|c|c|c|c|c|}
\hline Model migrant & Temperature & Time & $K_{\mathrm{LDPE} / \mathrm{naPP}}$ & Model migrant & Temperature & Time & $K_{\mathrm{LDPE} / \mathrm{naPP}}$ \\
\hline \multirow{6}{*}{ Benzophenone } & & 40 days & 0.35 & \multirow{6}{*}{ DPP } & \multirow{3}{*}{$60^{\circ} \mathrm{C}$} & 40 days & 0.13 \\
\hline & $60^{\circ} \mathrm{C}$ & 55 days & 0.33 & & & 55 days & 0.07 \\
\hline & & 70 days & 0.34 & & & 70 days & 0.10 \\
\hline & \multirow{3}{*}{$80^{\circ} \mathrm{C}$} & 25 days & - & & \multirow{3}{*}{$80^{\circ} \mathrm{C}$} & 25 days & 0.10 \\
\hline & & 40 days & 0.48 & & & 40 days & 0.09 \\
\hline & & 60 days & 0.45 & & & 60 days & 0.12 \\
\hline \multirow{6}{*}{ DPBD } & \multirow{3}{*}{$60^{\circ} \mathrm{C}$} & 40 days & 0.20 & & \multirow{3}{*}{$60^{\circ} \mathrm{C}$} & 40 days & 0.67 \\
\hline & & 55 days & 0.18 & & & 55 days & 0.55 \\
\hline & & 70 days & 0.20 & BHT & & 70 days & 0.55 \\
\hline & \multirow{3}{*}{$80^{\circ} \mathrm{C}$} & 25 days & - & ВП1 & \multirow{3}{*}{$80^{\circ} \mathrm{C}$} & 25 days & 0.84 \\
\hline & & 40 days & 0.27 & & & 40 days & 0.79 \\
\hline & & 60 days & 0.32 & & & 60 days & 0.97 \\
\hline \multirow{6}{*}{ Uvitex OB } & \multirow{3}{*}{$60^{\circ} \mathrm{C}$} & 40 days & 11.57 & \multirow{6}{*}{ Bisphenol A } & \multirow{3}{*}{$60^{\circ} \mathrm{C}$} & 40 days & 0.87 \\
\hline & & 55 days & 12.58 & & & 55 days & 0.91 \\
\hline & & 70 days & 4.67 & & & 70 days & 0.60 \\
\hline & \multirow{3}{*}{$80^{\circ} \mathrm{C}$} & 25 days & - & & \multirow{3}{*}{$80^{\circ} \mathrm{C}$} & 25 days & - \\
\hline & & 40 days & 1.35 & & & 40 days & 0.15 \\
\hline & & 60 days & 1.73 & & & 60 days & 0.11 \\
\hline \multirow{6}{*}{ ITX } & \multirow{4}{*}{$60^{\circ} \mathrm{C}$} & 40 days & 0.41 & & \multirow{3}{*}{$60^{\circ} \mathrm{C}$} & 40 days & 0.05 \\
\hline & & 55 days & 0.37 & & & 55 days & 0.05 \\
\hline & & 70 days & 0.41 & Triclosan & & 70 days & 0.04 \\
\hline & & 25 days & 0.57 & 11. & \multirow{3}{*}{$80^{\circ} \mathrm{C}$} & 25 days & - \\
\hline & \multirow[t]{2}{*}{$80^{\circ} \mathrm{C}$} & 40 days & 0.60 & & & 40 days & 0.06 \\
\hline & & 60 days & 0.60 & & & 60 days & 0.06 \\
\hline
\end{tabular}

be found distributed in the PP without being attached to the nanoparticles. These areas could attract and form hydrogen bonds and van der Waals forces bonds with migrants from the polyethylene. This ability to form secondary bond forces could explain the decrease in the values of $K_{\mathrm{LDPE} / \text { naPP }}$ found for all these molecules.

$R_{\mathrm{PP} / \text { naPP }}$ is a measure of the relative solubility of a substance in PP compared to its solubility in naPP. Relation $\left(R_{\mathrm{PP} / \mathrm{naPP}}\right)$ between $K_{\mathrm{LDPE} / \mathrm{PP}}$ and $K_{\mathrm{LDPE} / \mathrm{naPP}}$ at $60^{\circ} \mathrm{C}$ and $80^{\circ} \mathrm{C}$ for all substances studied is shown in Table $8 . R_{\mathrm{PP} / \mathrm{naPP}}$ is defined as

$$
R_{\mathrm{PP} / \mathrm{naPP}}=\frac{K_{\mathrm{LDPE} / \mathrm{PP}}}{K_{\mathrm{LDPE} / \mathrm{naPP}}} .
$$

When $R=1$, the migrant concentration in naPP at equilibrium equals the concentration in PP at equilibrium. $R$ is higher than 1 when more migrant is present into the naPP than in the PP. Only $\mathrm{BHT}$ at $60^{\circ} \mathrm{C}$ has an $R_{\mathrm{PP} / \text { naPP }}$ less than 1 but is very near to one. On the other hand, BPA has the highest $R_{\mathrm{PP} / \text { naPP }}$ (approximately 50 times more). These results show that all substances employed in this study have more preference for naPP than for PP. At $60^{\circ} \mathrm{C}$ (70 days) the affinity in decreasing order for naPP is triclosan $>\mathrm{BPA}>\mathrm{DPP}>$ $\mathrm{DPBD}>$ Benzophenone $>$ ITX $>$ Uvitex $>\mathrm{BHT}$. At $80^{\circ} \mathrm{C}(60$ days) the preference in decreasing order for naPP is BPA $>$ triclosan $>$ DPP $>$ DPBD $>$ Benzophenone $>$ Uvitex $>$ ITX $>$ BHT. Generally, the incorporation of Cloisite to PP increased the affinity of the selected substances compared to PP and LDPE.

These substances used in the preparation of food packaging could migrate into food. It is interesting to remark that the solubility of these substances has increased in the material with nanoparticles respect with the polypropylene alone. With this information, we can speculate about the behaviour of these kinds of plastics in contact with another element, for example, foodstuff. In this case, the increased solubility in nanoparticle polymer could represent a less quantity of substances that would pass away across the naPP and could be a good option to increase the safety and security in food packaging. More investigation about this approach must be carried out.

\section{Conclusions}

Partition coefficient of eight model substances between LDPE and PP and naPP was determined from their concentration in each polymer analysed. These concentrations were determined by using High-Performance Liquid Chromatography. The additives were of different chemical types, molecular weights and used for different functions.

The obtaining of partition coefficients lower than 1 indicates that affinity of additives is greater for naPP than $\mathrm{PP}$, even when substances with less tendency to migrate are present. Relation $\left(R_{\mathrm{PP} / \mathrm{naPP}}\right)$ between $K_{\mathrm{LDPE} / \mathrm{PP}}$ and $K_{\mathrm{LDPE} / \mathrm{naPP}}$ 


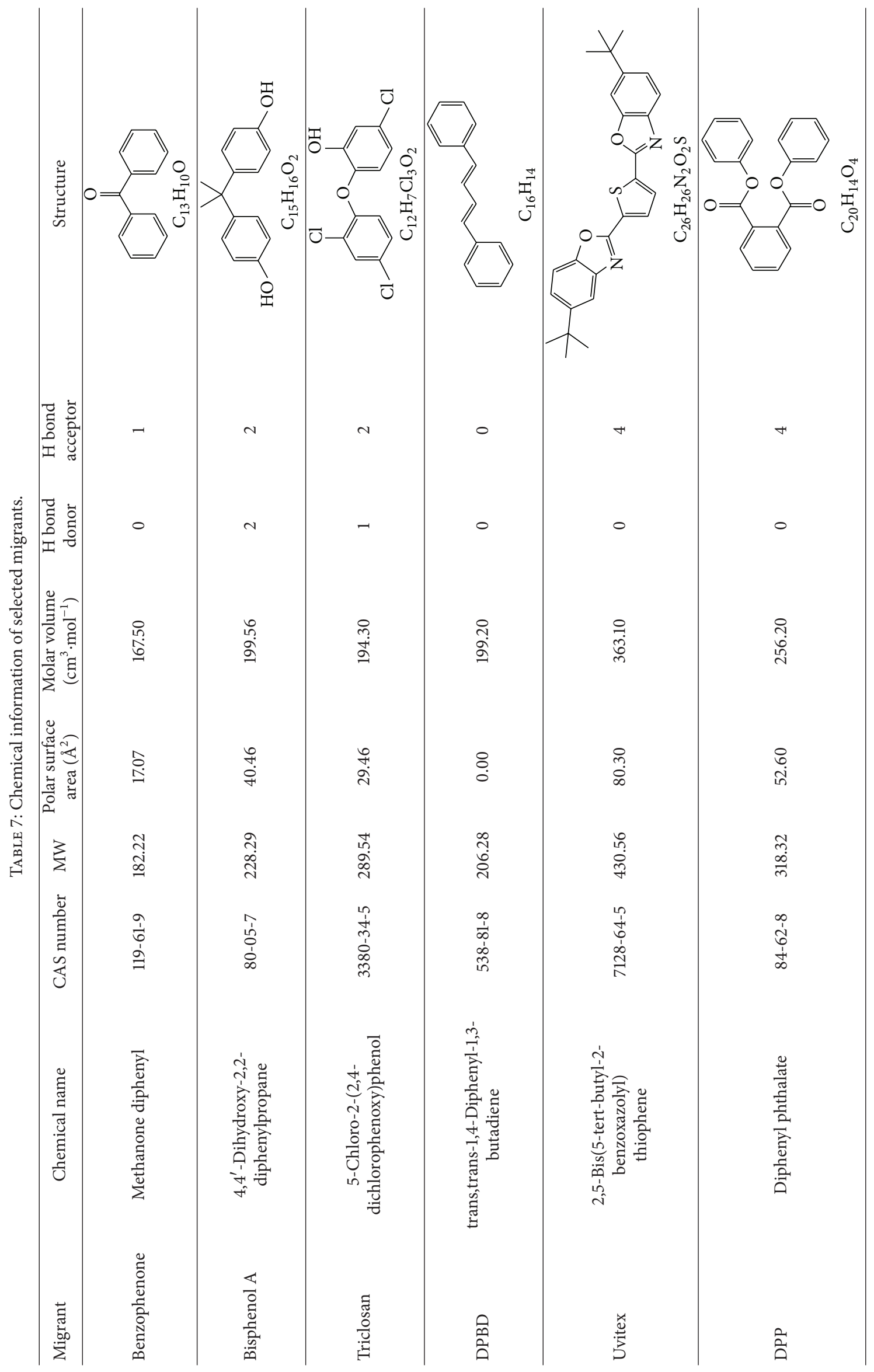




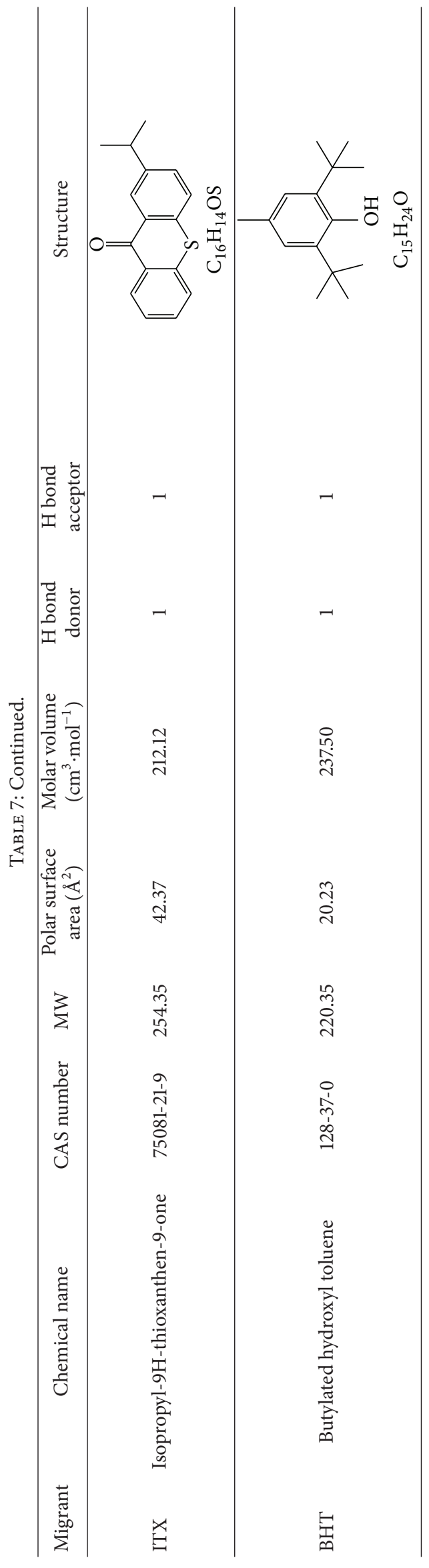


TABLE 8: Relation $\left(R_{\mathrm{PP} / \mathrm{naPP}}\right) K_{\mathrm{LDPE} / \mathrm{PP}} / K_{\mathrm{LDPE} / \mathrm{naPP}}$ at $60^{\circ} \mathrm{C}$ and $80^{\circ} \mathrm{C}$ for all substances studied.

\begin{tabular}{|c|c|c|c|c|c|c|c|}
\hline Model migrant & Temperature & Time & $R_{\mathrm{PP} / \mathrm{naPP}}$ & Model migrant & Temperature & Time & $R_{\mathrm{PP} / \mathrm{naPP}}$ \\
\hline \multirow{6}{*}{ Benzophenone } & & 40 days & 2.47 & \multirow{6}{*}{ DPP } & \multirow{3}{*}{$60^{\circ} \mathrm{C}$} & 40 days & 6.70 \\
\hline & $60^{\circ} \mathrm{C}$ & 55 days & 2.54 & & & 55 days & 13.84 \\
\hline & & 70 days & 2.55 & & & 70 days & 8.53 \\
\hline & \multirow{3}{*}{$80^{\circ} \mathrm{C}$} & 25 days & - & & \multirow{3}{*}{$80^{\circ} \mathrm{C}$} & 25 days & 11.92 \\
\hline & & 40 days & 2.15 & & & 40 days & 11.35 \\
\hline & & 60 days & 2.30 & & & 60 days & 10.02 \\
\hline \multirow{6}{*}{ DPBD } & \multirow{3}{*}{$60^{\circ} \mathrm{C}$} & 40 days & 5.69 & & \multirow{3}{*}{$60^{\circ} \mathrm{C}$} & 40 days & 0.93 \\
\hline & & 55 days & 6.33 & & & 55 days & 1.20 \\
\hline & & 70 days & 5.50 & BHT & & 70 days & 1.02 \\
\hline & \multirow{3}{*}{$80^{\circ} \mathrm{C}$} & 25 days & - & & \multirow{3}{*}{$80^{\circ} \mathrm{C}$} & 25 days & 1.07 \\
\hline & & 40 days & 4.82 & & & 40 days & 0.85 \\
\hline & & 60 days & 4.27 & & & 60 days & 0.89 \\
\hline \multirow{6}{*}{ Uvitex OB } & \multirow{3}{*}{$60^{\circ} \mathrm{C}$} & 40 days & 3.57 & \multirow{6}{*}{ Bisphenol A } & \multirow{3}{*}{$60^{\circ} \mathrm{C}$} & 40 days & 16.30 \\
\hline & & 55 days & 1.31 & & & 55 days & 15.54 \\
\hline & & 70 days & 2.02 & & & 70 days & 20.19 \\
\hline & \multirow{3}{*}{$80^{\circ} \mathrm{C}$} & 25 days & - & & \multirow{3}{*}{$80^{\circ} \mathrm{C}$} & 25 days & - \\
\hline & & 40 days & 3.34 & & & 40 days & 48.41 \\
\hline & & 60 days & 2.09 & & & 60 days & 54.19 \\
\hline \multirow{6}{*}{ ITX } & \multirow{4}{*}{$60^{\circ} \mathrm{C}$} & 40 days & 2.42 & \multirow{6}{*}{ Triclosan } & \multirow{3}{*}{$60^{\circ} \mathrm{C}$} & 40 days & 16.41 \\
\hline & & 55 days & 2.84 & & & 55 days & 16.98 \\
\hline & & 70 days & 2.44 & & & 70 days & 23.01 \\
\hline & & 25 days & 2.22 & & \multirow{3}{*}{$80^{\circ} \mathrm{C}$} & 25 days & - \\
\hline & \multirow[t]{2}{*}{$80^{\circ} \mathrm{C}$} & 40 days & 1.77 & & & 40 days & 18.28 \\
\hline & & 60 days & 2.03 & & & 60 days & 18.60 \\
\hline
\end{tabular}

at $60^{\circ} \mathrm{C}$ and $80^{\circ} \mathrm{C}$ shows that only $\mathrm{BHT}$ at $60^{\circ} \mathrm{C}$ has a $R_{\mathrm{PP} / \mathrm{naPP}}$ lower than 1 but is very near to 1 . On the other hand, BPA has the highest $R_{\mathrm{PP} / \mathrm{naPP}}$ (approximately 50 times more). The amount of migrants absorbed into PP and naPP depends partially on the nature of the polymer and slightly on the chemical features of the model migrant. Factors that affected absorption include molecular size of migrants, polarity, and solubility properties of both the polymers and the migrants. The results obtained could prove the presence of interactions between the model migrants and the naPP. As far as we know there are no published studies over the partition coefficient of model migrants into nanocomposite polypropylene films. For that reason, the results obtained in the present study contribute to a better understanding of mass transport processes of migrants to nanocomposite film.

\section{Conflict of Interests}

The authors declare that there is no conflict of interests regarding the publication of this paper.

\section{Acknowledgments}

The study was financially supported by the Xunta de Galicia (Project no. INCITE08PXIB203096). R. Sendon is grateful to the "Parga Pondal" Program financed by "Consellería de
Innovación e Industria, Xunta de Galicia” for her postdoctoral contract.

\section{References}

[1] I. S. Arvanitoyannis and L. Bosnea, "Migration of substances from food packaging materials to foods," Critical Reviews in Food Science and Nutrition, vol. 44, no. 2, pp. 63-76, 2004.

[2] A. T. Sanches Silva, J. M. Cruz Freire, R. Sendón, R. Franz, and P. P. Losada, "Migration and diffusion of diphenylbutadiene from packages into foods," Journal of Agricultural and Food Chemistry, vol. 57, no. 21, pp. 10225-10230, 2009.

[3] S. Gärtner, M. Balski, M. Koch, and A. Nehls, "Analysis and migration of phthalates in infant food packed in recycled paperboard," Journal of Agricultural and Food Chemistry, vol. 57, no. 22, pp. 10675-10681, 2009.

[4] A. Leo, C. Hansch, and D. Elkins, "Partition coefficients and their uses," Chemical Reviews, vol. 71, no. 6, pp. 525-616, 1971.

[5] E. A. Tehrany and S. Desobry, "Partition coefficients in food/packaging systems: a review," Food Additives \& Contaminants, vol. 21, no. 12, pp. 1186-1202, 2004.

[6] J. Crank, The Mathematics of Diffusion, Clarendon Press, Oxford, UK, 2nd edition, 1975.

[7] J. M. Cruz, A. T. Sanches Silva, R. Sendón García, R. Franz, and P. Paseiro Losada, "Studies of mass transport of model chemicals from packaging into and within cheeses," Journal of Food Engineering, vol. 87, no. 1, pp. 107-115, 2008. 
[8] S. G. Gilbert, J. Miltz, and J. R. Giacin, "Transport considerations of potential migrants from food packaging materials," Journal of Food Processing and Preservation, vol. 4, no. 1-2, pp. 27-49, 1980.

[9] M. J. Shepherd, "Trace contamination of foods by migration from plastics packaging-a review," Food Chemistry, vol. 8, no. 2, pp. 129-145, 1982.

[10] A. P. O'Brien, I. Cooper, and P. A. Tice, "Correlation of specific migration (Cf) of plastics additives with their initial concentration in the polymer (Cp)," Food Additives \& Contaminants, vol. 14, no. 6-7, pp. 705-719, 1997.

[11] A. O’Brien, A. Goodson, and I. Cooper, "Polymer additive migration to foods - a direct comparison of experimental data and values calculated from migration models for high density polyethylene (HDPE)," Food Additives \& Contaminants, vol. 16, no. 9, pp. 367-380, 1999.

[12] W. Summerfield and I. Cooper, "Investigation of migration from paper and board into food-development of methods for rapid testing," Food Additives and Contaminants, vol. 18, no. 1, pp. 77-88, 2001.

[13] D. A. Pereira de Abreu, J. M. Abreu, I. Angulo, and P. Paseiro Losada, "Mass transport studies of different additives in polyamide and exfoliated nanocomposite polyamide films for food industry," Packaging Technology and Science, vol. 23, no. 2, pp. 59-68, 2010.

[14] P. C. Lebaron, Z. Wang, and T. J. Pinnavaia, "Polymer-layered silicate nanocomposites: an overview," Applied Clay Science, vol. 15, no. 1-2, pp. 11-29, 1999.

[15] S. S. Ray and M. Okamoto, "Polymer/layered silicate nanocomposites: a review from preparation to processing," Progress in Polymer Science, vol. 28, no. 11, pp. 1539-1641, 2003.

[16] D. A. Pereira de Abreu, P. Paseiro Losada, I. Angulo, and J. M. Cruz, "Development of new polyolefin films with nanoclays for application in food packaging," European Polymer Journal, vol. 43, no. 6, pp. 2229-2243, 2007.

[17] D. Pereira, P. P. Losada, I. Angulo, W. Greaves, and J. M. Cruz, "Development of a polyamide nanocomposite for food industry: morphological structure, processing, and properties," Polymer Composites, vol. 30, no. 4, pp. 436-444, 2009.

[18] Commission Regulation, “(EU) No 10/2011 of 14 January 2011 on plastic materials and articles intended to come into contact with food," Official Journal of the European Union, vol. L12, pp. $1-132,2011$.

[19] O. Vitrac, B. Challe, J.-C. Leblanc, and A. Feigenbaum, "Contamination of packaged food by substances migrating from a direct-contact plastic layer: assessment using a generic quantitative household scale methodology," Food Additives and Contaminants, vol. 24, no. 1, pp. 75-94, 2007.

[20] A. T. Sanches-Silva, S. Pastorelli, J. M. Cruz, C. Simoneau, I. Castanheira, and P. Paseiro-Losada, "Development of a method to study the migration of six photoinitiators into powdered milk," Journal of Agricultural and Food Chemistry, vol. 56, no. 8, pp. 2722-2726, 2008.

[21] B. Jose, J. H. Ryu, B. G. Lee, H. Lee, Y. S. Kang, and H. S. Kim, "Effect of phthalates on the stability and performance of AgBF4PVP membranes for olefin/paraffin separation," Chemical Communications, vol. 20, pp. 2046-2047, 2001.

[22] C. A. Staples, P. B. Dorn, G. M. Klecka, S. T. O’Block, and L. R. Harris, "A review of the environmental fate, effects, and exposures of bisphenol A," Chemosphere, vol. 36, no. 10, pp. 2149-2173, 1998.
[23] T. Begley, L. Castle, A. Feigenbaum et al., "Evaluation of migration models that might be used in support of regulations for food-contact plastics," Food Additives \& Contaminants, vol. 22, no. 1, pp. 73-90, 2005.

[24] A. Ravve, Principles of Polymer Chemistry, Plenum Press, New York, NY, USA, 1995.

[25] P. Landy, C. Druaux, and A. Voilley, "Retention of aroma compounds by proteins in aqueous solution," Food Chemistry, vol. 54, no. 4, pp. 387-392, 1995.

[26] M. Fukamachi, T. Matsui, Y.-H. Hwang, M. Shimoda, and Y. Osajima, "Sorption behavior of flavor compounds into packaging films from ethanol solution," Journal of Agricultural and Food Chemistry, vol. 44, no. 9, pp. 2810-2813, 1996.

[27] E. A. Tehrany, C. Mouawad, and S. Desobry, "Determination of partition coefficient of migrants in food simulants by the PRV method," Food Chemistry, vol. 105, no. 4, pp. 1571-1577, 2007.

[28] M. Shimoda, T. Ikegami, and Y. Osajima, "Sorption of flavour compounds in aqueous solution into polyethylene film," Journal of the Science of Food and Agriculture, vol. 42, no. 2, pp. 157-163, 1988.

[29] T. J. Nielsen, I. M. Jägerstad, and R. E. Öste, "Study of factors affecting the absorption of aroma compounds into low-density polyethylene," Journal of the Science of Food and Agriculture, vol. 60, no. 3, pp. 377-381, 1992.

[30] Y.-H. Hwang, T. Matsui, T. Hanada, M. Shimoda, K. Matsumoto, and Y. Osajima, "Desorption behavior of sorbed flavor compounds from packaging films with ethanol solution," Journal of Agricultural and Food Chemistry, vol. 48, no. 9, pp. 4310-4313, 2000.

[31] S. Chung and R. Villota, "Changes in partition coefficients of alcohols as affected by the presence of various food solids," Journal of Food Process Engineering, vol. 13, no. 2, pp. 169-189, 1990.

[32] M. Kawasumi, N. Hasegawa, M. Kato, A. Usuki, and A. Okada, "Preparation and mechanical properties of polypropylene-clay hybrids," Macromolecules, vol. 30, no. 20, pp. 6333-6338, 1997.

[33] P. Maiti, P. H. Nam, M. Okamoto, N. Hasegawa, and A. Usuki, "Influence of crystallization on intercalation, morphology, and mechanical properties of polypropylene/clay nanocomposites," Macromolecules, vol. 35, no. 6, pp. 2042-2049, 2002.

[34] E. Manias, A. Touny, L. Wu, K. Strawhecker, B. Lu, and T. C. Chung, "Polypropylene/montmorillonite nanocomposites. Review of the synthetic routes and materials properties," Chemistry of Materials, vol. 13, no. 10, pp. 3516-3523, 2001.

[35] D. E. Clark, "Rapid calculation of polar molecular surface area and its application to the prediction of transport phenomena. 1. Prediction of intestinal absorption," Journal of Pharmaceutical Sciences, vol. 88, no. 8, pp. 807-814, 1999. 

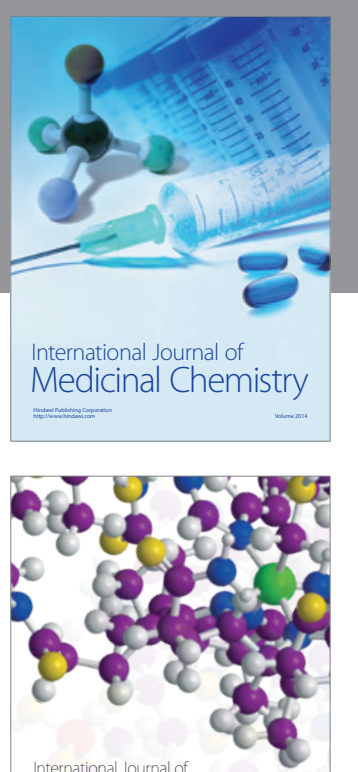

Carbohydrate Chemistry

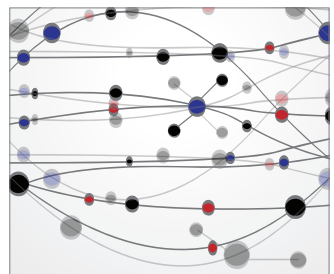

The Scientific World Journal
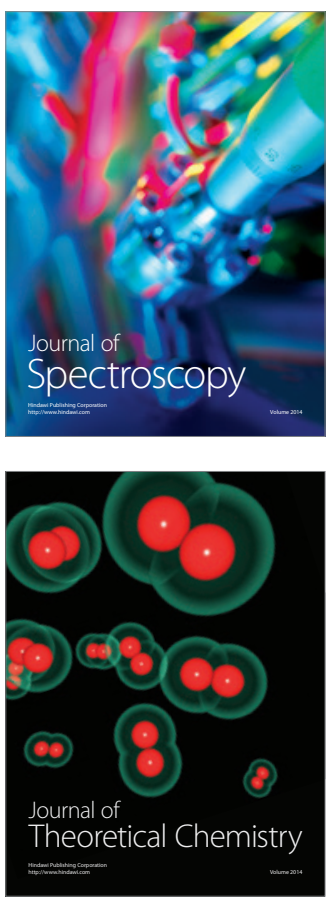
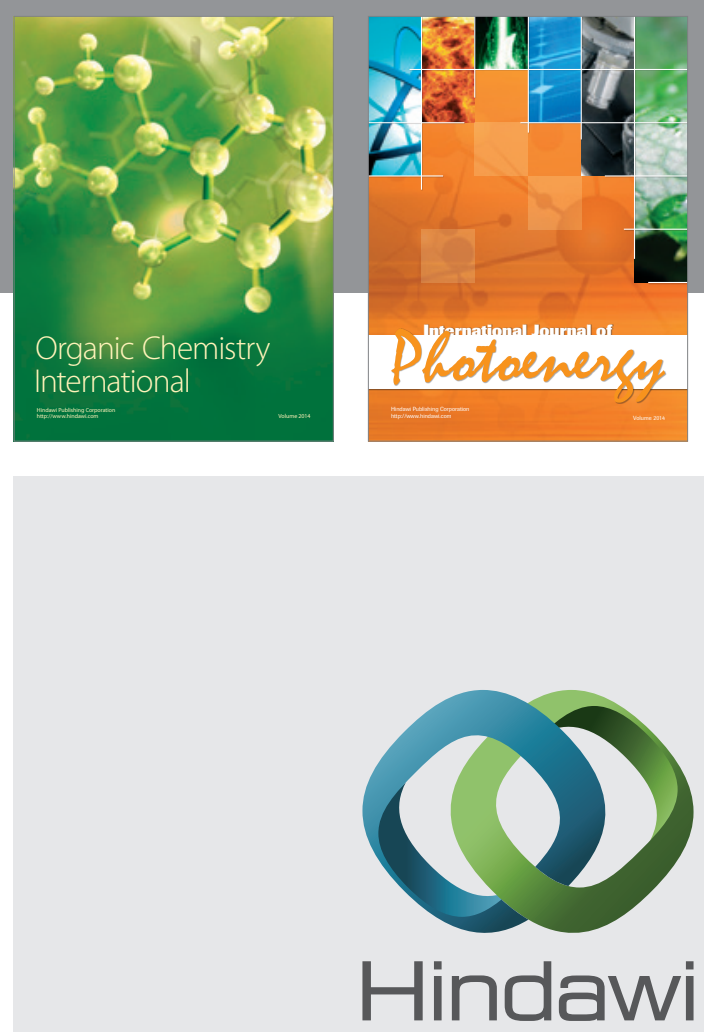

Submit your manuscripts at

http://www.hindawi.com

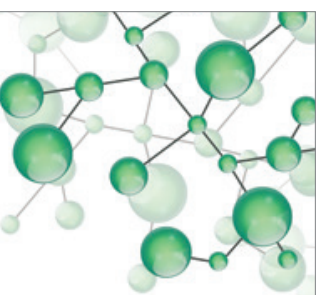

International Journal of

Inorganic Chemistry

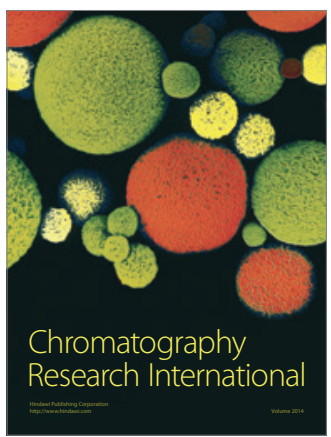

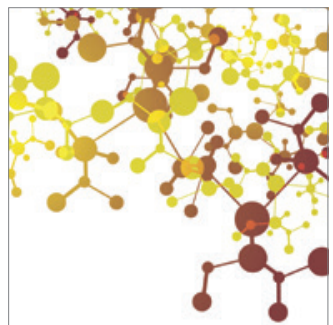

Applied Chemistry
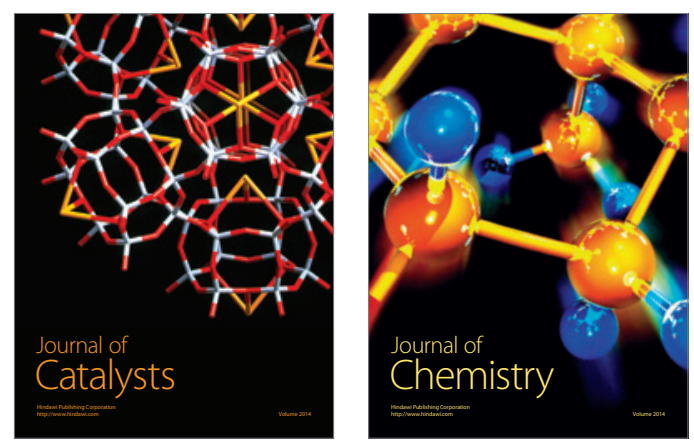
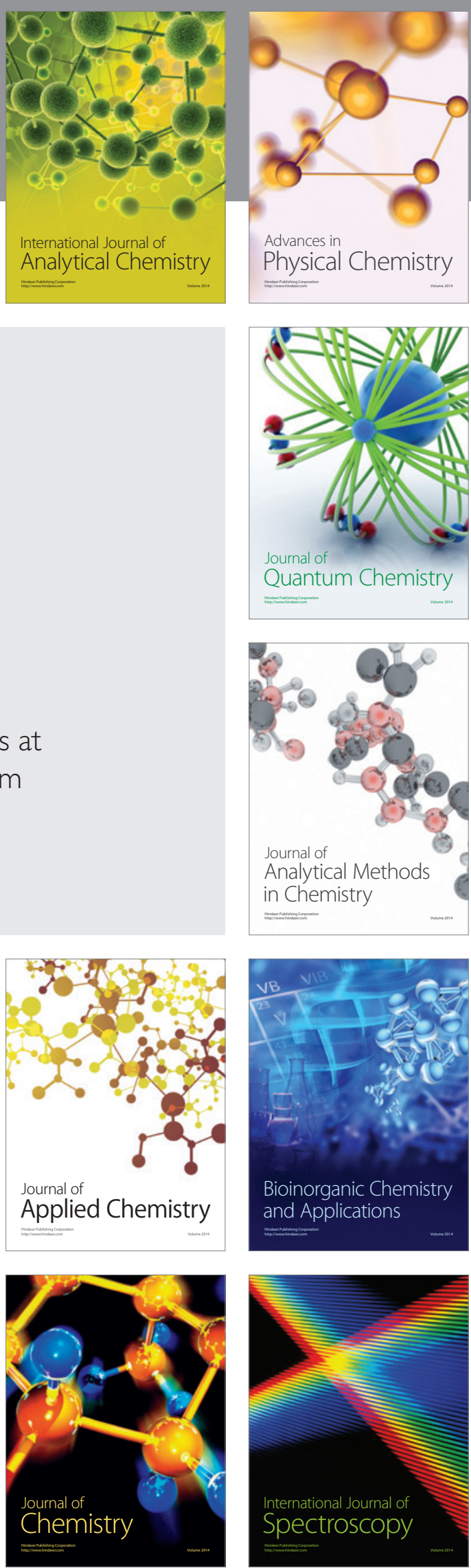